\title{
VARIA
}

\section{DOS BODEGONES DE FRANCISCO BARRANCO}

Bien poco se sabe del pintor andaluz, probablemente sevillano, Francisco Barranco, fuera de las brevísimas líneas que le dedicó Ceán Bermúdez situándolo en Sevilla en $1646^{1}$, de la mención de tres bodegones suyos presentes en 1650 en una colección sevillana ${ }^{2}$, y de la existencia de un notable Bodegón de cocina con aves muertas y servicio de chocolate, firmado en 1647, que erróneamente dí a conocer bajo el nombre de Francisco Sarabia por una mala lectura de la firma - a través de una deficiente fotografía $-{ }^{3}$, que fue luego correctamente leída y publicado el lienzo «in extenso» por Peter Cherry ${ }^{4}$.

Un afortunado azar me permite hoy publicar otros dos bodegones de calidad y carácter análogo al conocido, firmados también, como él, en 1647, que vienen a ratificar la excelente calidad del pintor y su maestría en la representación de las cosas inertes y del pelaje y plumaje de los animales, en medida no inferior a otros artistas mejor conocidos y apreciados, tanto en Sevilla como en Madrid, por los mismos años.

Los cuadros que ahora se presentan son dos tablas, de dimensiones $0,31 \times 0,52$, ambas firmadas, pertenecientes a una colección privada suramericana (figs. 1 y 2 ).

Una de ellas presenta (fig. 1), en una disposición escalonada, análoga a la del bodegón ya conocido, una serie de objetos dispuestos al azar. En la parte derecha, en un plano elevado, se advierte una taza lacada de tipo mexicano, semejante a las que aparecen en el Bodegón ya conocido y en otros de Juan de Zurbarán, y una tela o paño rojo con rayas oscuras y flecos, también muy próximo al que se veía en el citado bodegón. En un plano más bajo y sobre una especie de repisa que avanza hacia el espectador, se sitúan unas aves muertas de distintos plumajes, una de las cuales muestra su cabeza colgando en un alarde ilusionístico. En segundo término, en el centro y marcando una diagonal muy acusada, una vasija de cobre boca abajo, apoya sobre el escalón y enlaza con las aves del centro. A la izquierda, sobre un saliente lateral de la repisa, un conejo vivo roe unas hojas de col y en el fondo una jarra metálica de ancha asa se destaca, vibrante, en la sombra.

1 Ceán Bermúdez, Diccionario, 1800, Vol. I. p. 93.

2 W. Jordan y Peter Cherry, en el Catálogo de la Exposición Spanish Still-life from Velázquez to Goya, Londres National Gallery, 1995, p. 195, nota 6.

3 A.E. Pérez Sánchez, «Miscelánea seiscentista» en Cinco siglos de Arte en Madrid, III Jornadas de Arte, C.S.I.C., 1991, p. 318-319.

4 P. Cherry en Tres siglos de pintura, Madrid, Caylus, 1995, p. 140-143. 

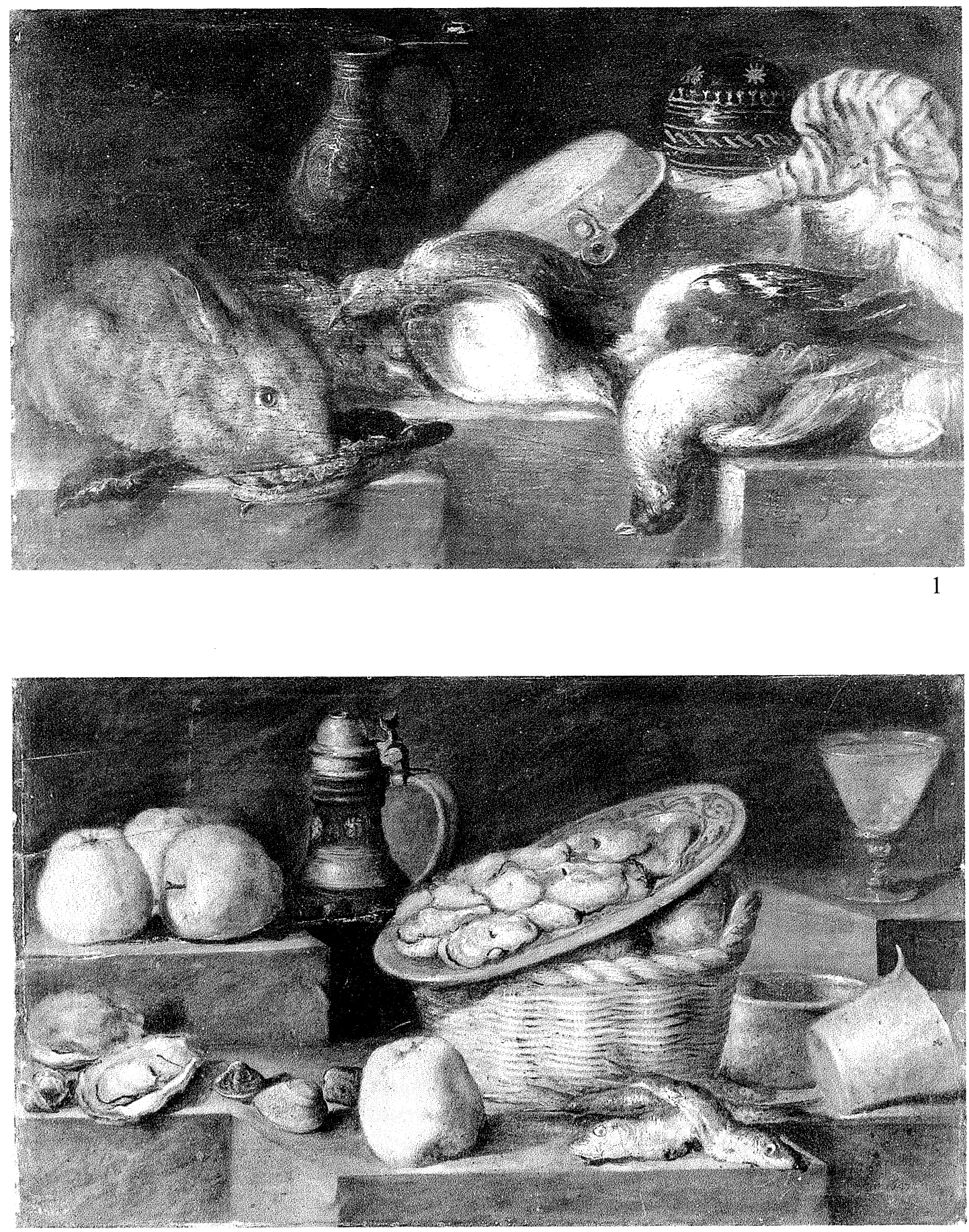

Figura 1. Francisco Barranco. Bodegón, 1647, Óleo sobre madera, 31 x $52 \mathrm{cms}$.

Figura 2. Francisco Barranco. Bodegón, 1647, Óleo sobre madera, 31 x 52 cms. 
Aunque el cuadro, como su compañero, está muy sucio y necesitado de una limpieza que permita valorar mejor sus calidades, se advierte en él la ya conocida maestría en la representación material de las cosas y una pincelada suelta y grasa, más próxima a los modos madrileños de un Pereda o de un Cerezo, que a las precisiones modeladoras de Juan de Zurbarán, o a la delicadeza aterciopelada de Pedro de Camprobín, sus contemporáneos sevillanos.

La tabla está firmada en el antepecho de la derecha: «fran ${ }^{\mathrm{co}}$ Barranco fac/1647».

La otra tabla (fig. 2) se dispone de modo muy semejante pero con una cierta voluntad de invertirse respecto a la otra, que seguramente se concibió como compañera. Si en aquélla las repisas se disponen de modo que los laterales avanzan dejando un hueco central, en ésta, el antepecho se proyecta en el centro, dejando los laterales retraídos.

El primer término, avanzado, lleva unas sardinas o arenques, una gruesa manzana y unas almejas y, tras ello, un cesto de mimbre con frutas sobre el que apoya, en acusada diagonal, un plato de cerámica con ostras separadas de su concha. A la derecha, un tanto retrasada, se ve una vasija de cobre y, en un plano superior, una fina copa de vino rosado. A la izquierda, en primer término, unas ostras, con su concha, y detrás, en un plano superior, tres gruesas manzanas. Al fondo se recorta una jarra metálica con tapa y gran asa. También esta tabla está firmada con claridad, en la parte inferior derecha: «fran ${ }^{\mathrm{co}}$ barranco/fecit 1647 ».

Aquí, como en el cuadro compañero, se advierte una especial maestría en el tratamiento de la materia de las cosas. Los peces, resueltos con una materia espesa y grumosa, el cobre, de tan nítidos reflejos y las frutas, de muy rotunda materia, dan la medida de su maestría. Y todo ello, como observó Cherry, visto bajo una luz difusa, que difiere radicalmente del tenebrismo de Juan de Zurbarán, y sitúa a su autor en un lugar de privilegio en la transformación del bodegón español hacia su dimensión más barroca. La tonalidad, unificada en clave de castaños dorados, con las notas más cálidas del brillo cobrizo de las vasijas o el rojo intenso de la tela en el primero, hace evocar, aunque con otra técnica, ciertos bodegones holandeses en los que incluso el motivo del roedor — aquí conejo- se introducía.

Si no debe desdeñarse la hipótesis de Cherry de que Barranco visitase Madrid, y pudiese haber apreciado allí «la densa textura de los bodegones de Antonio de Pereda y quizás los de Francisco Palacios, que como discípulo de Velázquez trabajaba en un estilo deshecho y atmosférico», no debe tampoco olvidarse que las obras más «densas» y pastosas de Pereda son de 1651 (Bodegones de Lisboa y de colección finlandesa hoy en el mercado americano) y que las de Pacheco, en la Col. Harrach, son de 1648, es decir, posteriores a los conocidos de Barranco ${ }^{5}$.

Y aún puede añadirse que Pereda es siempre más preciso y modelador en su técnica y Palacios menos denso de materia y más aterciopelado en el efecto general.

La calidad objetiva de las tablitas y el lugar en que se sitúan en la cronología del bodegón hispano, hace doblemente importante su aparición, y obligan a tomar en consideración al autor a la hora de definir y precisar la evolución del género entre nosotros.

Quizás una atenta indagación en las colecciones sevillanas permita identificar más obras suyas y perfilar mejor a un artista que se sitúa, sin duda, entre lo más «moderno» de su tiempo y su género.

Alfonso E. PÉREZ SÁNCHEZ Universidad Complutense

5 Para la evolución general del género de Bodegón en España, véanse el citado Catálogo de Jordan-Cherry de 1995 y el texto de A.E. Pérez Sánchez, La nature morte espagnole du XVII siècle a Goya, Friburgo, 1987. 